\title{
Homelessness and Strategies of Identity Maintenance: A Participant Observation Study
}

\author{
ALICE FARRINGTON and W. PETER ROBINSON* \\ Department of Psychology, University of Bristol, UK
}

\begin{abstract}
In order to investigate identity maintenance strategies used by a low status group, a covert participant observation study was conducted in a shelter for the homeless. From Social Identity Theory and previous research on the homeless, it was hypothesized that the identity maintenance strategies used would differ as a function of longevity of homelessness: the shortterm homeless $(<2$ years) would be less likely to identify themselves as homeless (social mobility), while the longer-term homeless ( $>2$ years) would identify themselves as homeless but engage in various types of social creativity to mitigate their situation. In addition to the strategies described in SIT, it was conjectured that some of the longest-term homeless would have given up making any intergroup or other social comparisons. Of the various strategies found, some were beyond SIT. The pattern of strategy use was best interpreted mainly as a function of longevity of homelessness, but this was moderated by both experience and personality. A trajectory of change in identity strategies with longevity of homelessness was offered as a plausible frame of reference for further research. Methodological limitations, implications for Social Identity Theory and recommendations for improving the situation of the homeless were discussed. Copyright (C) 1999 John Wiley \& Sons, Ltd.
\end{abstract}

Key words: homelessness; identity maintenance; comparison making

\section{HOMELESSNESS}

There is no generally accepted definition of homelessness. To be homeless literally means to be without a home. However, more useful definitions extend beyond to those who are physically without shelter. For example, Kelling (1991, p.ii) stated: "Homelessness is much more than "rooflessness": it is the lack of a secure and satisfactory home'.

Until the early 1980s, homelessness remained invisible to many people (Hombs, 1992). Since then, particularly in the USA, attention has been drawn to the phenomenon so that by 1994 Snow, Anderson and Koegel (p.461) could write that, 'no social aggregation has been examined so intensely during the past decade as

\footnotetext{
* Correspondence to: Professor W. P. Robinson, Department of Psychology, University of Bristol, 8 Woodland Road, Bristol, BS8 1TN. Tel: 0117 9288451. Fax: 01179288588. 
the homeless'. However, the academic attention has usually been in the form of questionnaire surveys, mostly concerned with the demographics (e.g. Rossi, Wright, Fisher and Willis, 1987), survival needs (e.g. Cohen, Teresi, Holmes and Roth, 1988a), and presumed disabilities of the homeless (e.g. Fischer and Breakey, 1991). Notably exceptions are Snow and Anderson (1987, 1993), Baumann and Grigsby (1988; Grigsby, Baumann, Gregorich and Roberts-Gray, 1990) and Pollio (1994; 1995; Pollio and Kasden, in press) who have asked questions about the homeless, both as a social phenomenon and as a community issue. Although the exact numbers of homeless people in the UK are unknown, Barnett (1997) estimates the number at 150,000 and records indicate that the homeless population is increasing (Fisher and Collins, 1993).

The homeless have been described as 'the bilges of our society' (Sandford, 1971, p. 9) and undoubtedly constitute a low-status and stigmatized group. The majority cannot hide their stigmata (Anderson, Snow and Cress, 1994) and are aware of their low status (Pollio and Kasden, in press). Furthermore, homeless people are frequently reminded of their status by the domiciled population (Snow and Anderson, 1987). An interview with a homeless man by Larkin (1995, p. 18) elicited this reply:

I hate the attitudes of some people who look down on me as if I am scum. I've had beer thrown at me ... I woke up one morning and found that someone had pissed on me while I was asleep ... But I think what's worse is the amount of people who completely ignore me, they just walk on by as though I don't exist.

The social identity and self-esteem of the homeless is presumed to be threatened by their condition as a low-status group (Breakwell, 1992), but the strategies they use for coping with this threat have largely been neglected in research. This study aims to redress this and to explore their identity maintenance strategies using Social Identity Theory (SIT; Tajfel and Turner, 1979) as the framework for so doing.

\section{SOCIAL IDENTITY THEORY}

Tajfel (1982, p. 2) defined social identity (SI) as:

That part of the individual's self-concept which derives from their knowledge of their membership of a social group (or groups) together with the value and emotional significance attached to that membership.

Typically, such membership is categorical, and the boundaries between social categories are rendered clear enough to construct qualitatively distinctive divisions. In contrast, personal identity (PI) refers to quantifiable characteristics of the individual, typically expressed as traits whose values are determined through comparisons of self and others, especially ingroup members.

Social Identity Theory was proposed by Tajfel and Turner (1979; Tajfel 1978, 1981 , 1982) to contribute a social psychological explanation of social conflicts. It drew on Festinger's (1954) work on social comparison, which claimed that all individuals aimed to preserve or achieve a satisfactory self-concept and wished to avoid negative self-esteem. This was achieved through making favourable comparisons with similar others. Tajfel claimed that group membership also contributed positively or negatively to an individual's self-concept. Hence, people were thought to strive for positive group evaluations when social identities were salient. In this case, 
social comparisons were made at a group level. If the ingroup could be seen as superior to comparison groups on some valued dimension then group members could 'bask in reflected glory', increasing or maintaining their positive self esteem.

\section{COPING WITH NEGATIVE SOCIAL IDENTITIES}

Tajfel and Turner (1979) acknowledged that, under certain circumstances, it might be difficult for members of low status groups to find bases for an intergroup comparison which would provide them with a positive social identity. If so, this would confer a negative SI on members, and hence negative self-esteem. When this occurred, it was argued that individuals would be motivated to remedy the situation. Tajfel and Turner proposed three possible means:

Social mobility: Leave the group and join another with more positive qualities;

Social change: Change the more general social structure of society so that the group will be more favourably evaluated in future;

Social creativity: Seek new bases for comparison giving more favourable outcomes either by changing the dimensions for comparison or by switching the comparison group.

SIT should be applicable to groups such as the homeless. As a low status and multiply disadvantaged group, a negative identity would be expected in the homeless, leading to the pursuit of one or more of the above coping strategies.

The only previous work that has explicitly studied identity in the homeless was conducted by Snow and Anderson $(1987,1993)$, who completed a two year ethnographic field study in Austin, Texas. Although Snow and Anderson claimed to have concentrated on PI, their conceptualisation of identity and PI differ from those used in European social psychology. Inspection of their data shows a variety of identity maintenance strategies pertaining to both PI and SI. Therefore, although Snow and Anderson make no reference to SIT, their results can be re-interpreted in line with it.

Tajfel and Turner claimed that the utilisation of self-enhancement strategies was affected by interpersonal variables within groups. For example, a higher identification with the ingroup label and with ingroup members should increase the frequency of favourable intergroup comparisons. Snow and Anderson (1987) found that generally people who had been homeless for over two years identified more with the ingroup and with other ingroup members than people who had been homeless for less than two years. On this basis, the phrase short-term homeless will be used here to refer to people who have been homeless for less than two years, while people who have been homeless for two years or over will be referred to as long-term homeless.

\section{Social mobility}

For those who decide to use social mobility as the means for repairing negative social identity the boundaries between themselves and higher status groups need to be perceived as permeable (Tajfel and Turner, 1979). Snow and Anderson (1987) found dissociation from the group label and from other homeless individuals were both used by the short-term homeless, and both can be seen as strategies related to social mobility; positive identity is preserved by an alternative identification to homelessness. 
A further related method is to deny membership of the low status group. Studies of homeless people have identified some individuals who deny that they are homeless (e.g. Pollio and Kasden, in press). Karasawa (1988) found that denial of group membership was more common in members of low status groups whose identification with the ingroup was weak. These empirical precedents imply that both dissociation and denial are used, particularly by the short term homeless. In contrast, since it is access to suitable accommodation that distinguishes the homeless from the domiciled, the lack of perceived opportunities and resources to obtain housing, particularly for the longer-term homeless, may preclude their use of social mobility as an identity maintenance strategy.

\section{Social change}

It is unlikely that the homeless will attempt to overthrow the social order and create a dramatic social change. Neither have they the power to change their negative image to a positive social representation of homelessness which would allow future intergroup comparisons to be more favourable and thus alleviate the negativity of their selfesteem. Such social change is improbable considering that the existing Western dominant social representation of the homeless consists of 'filthiness, laziness, helplessness, alcoholism, mental illness and violence' (Anderson et al., 1994, p. 123).

\section{Social creativity}

Is social creativity an option? It has been proposed that certain dimensions for comparison are universal. For example, Brewer (1986, in Deaux et al., 1993) showed that the tendency to view the ingroup as morally superior and trustworthier exists in many cultures. An example of the homeless using altruism as a dimension for favourable comparisons was observed in one of the participants in Snow and Anderson's study (1993, p. 173):

People look down on the homeless, but there's more willing to give you the shirt off their back down here than anywhere else.

This altruistic 'norm' to share resources and offer support among homeless people has been noted in homeless women (Russell, 1991), in homeless men (Pollio and Kasden, in press), and in older homeless people in London (Crane, 1990). Hence, reciprocated sharing may be a dimension that the homeless can use for favourable comparisons with other groups. such intergroup comparisons are likely to be used only by individuals with a strong homeless identification, i.e. the long-term homeless.

Wills (1981) proposed that under conditions of threat, people make comparisons with people worse off than themselves, or downward social comparisons. For the homeless, it may not be easy to find a similar group perceived as worse off than themselves on a salient dimension.

\section{Still negative identity?}

This brief survey of the options for the homeless to repair their negative social identity indicates some possibilities, but it may also be that the absence of comparison 
dimensions and groups which would yield favourable comparisons may lead some homeless people to search for further social creativity options not previously included in SIT. Possibilities are: construction of a group from within the 'ingroup' for generating favourable intersubgroup comparisons; increasing intragroup comparisons while avoiding intergroup comparisons; or avoiding social comparisons altogether. The first option continues the use of SI and can be considered as a variant of social creativity, whereas the second option moves the comparison from SI to PI. The last option, if found, would necessitate a re-evaluation of the current formulation of SIT.

Consistent with the first option, Phillimore (1979) completed a participant observation study with a homeless group in London and found that they identified themselves as 'dossers' rather than as 'jake-drinkers'. For example, the homeless who congregated habitually around a fire were condemned as jake-drinkers, despite the fact that many of the dossers sporadically visited the fire. Phillimore noted that the usual reaction of those who were labelled as jake-drinkers was to deny that there was any difference between themselves and the dossers who discredited them, claiming; 'We're all dossers here' (p.33). They also added that the real jake-drinkers were another group. Such strategies are ingenious solutions to the problem of maintaining a positive social identity in a low status group.

Snow and Anderson (1987) also found examples of this strategy. It was used most frequently by people who had been homeless for between two and four years and commonly comprised people independent of institutions derogating those who were dependent on institutional aid for food and/or shelter.

In respect of the second option, Crocker and Major (1989) hypothesized that individuals in stigmatized groups deliberately avoid comparisons of themselves with members of other groups to evade negative self-esteem; instead, stigmatized people compared themselves selectively with other ingroup members on attributes on which they personally fared well (PI).

Crocker and Major suggested that an ability to avoid intergroup comparisons took time to develop. If so, it would be people who had been homeless longer who would be expected to make more intragroup comparisons. The essence of this form of comparison is a switch from a SI basis to a PI one. Consistent with this idea, Snow and Anderson (1987) noted that many of their longer-term homeless engaged in 'rolespecific embracement', which entailed describing themselves as expert beggars or as people who shared scarce resources, for example. This category might therefore be reinterpreted as individual assertions of the outcomes of favourable intragroup comparisons using dimensions valued by the homeless group.

Theoretically, a situation may exist where neither favourable intergroup nor intragroup comparisons are possible. For example, a long-term homeless person may identity him/herself as homeless and perceive the homeless as a low-status group, but not be able to fit into a positively valued subgroup or have perceived personal qualities for positive intragroup comparisons (see Breakwell, 1986a, 1986b, for a comparable approach).

Snow and Anderson (1987) found some cases among the long-term homeless of identification as a prototypical ingroup member, people who immediately identified themselves as a 'tramp' or 'bum'. The researchers argued that these individuals derived their self-esteem from this identification and categorization. However, there was no indication that this involved explicit comparisons with other categories. 
Although non-comparison has been virtually ignored by researchers (Foddy and Crundall, 1993), Breakwell suggested that it might be a valid route for maintaining self-esteem. She hypothesized that multiply disadvantaged groups had learned that social comparisons 'bring nothing but grief' (1986a, p. 176).

\section{PROVISIONAL GENERALIZATIONS}

If the above analysis is sound, then the categorizations and the bases of social comparisons that the homeless will make should change with the duration and circumstances of their homelessness. Other things being equal, their progress should be consistent with the following statements:

1 Homeless people will not attempt to use a positive identity maintenance strategy that changes dominant social representations of the homeless.

2. Shorter-term homeless are likely to have a lower identification with the group label and with ingroup members than longer-term homeless.

3. Shorter-term homeless are more likely to attempt to leave the group, to deny group membership, and to dissociate themselves from group members or the group label. Each of these means can yield favourable comparisons.

4. Those who have been homeless for two to four years will be disposed to construct a group for themselves from within the homeless for making favourable downward intergroup comparisons.

5. The longer-term homeless will make intergroup comparisons using dimensions such as trustworthiness and altruism.

6. The longer-term homeless will make more intragroup comparisons than shorterterm homeless.

7. The longer-term homeless will be more likely to use role-specific characteristics for making personally favourable intragroup comparisons.

8. Some of the longer-term homeless will not make any social comparisons.

Given the current state of knowledge, it is not yet appropriate to set up a predictive model, but it is sensible to use the eight statements as a frame of reference for goodness of fit. Can the individuals from a sample of homeless persons be plausibly integrated within such a framework?

\section{METHOD}

\section{Methods}

The design was a covert participant observation field study $(n=21)$. The hypothesized best single approximate index of the relevant independent variables was longevity of homelessness, and the dependent variables were the identity maintenance strategies used by the homeless. Covert participant observation was deemed to be the only feasible ecologically valid methodology. Any disclosure or negotiation would have precluded the conduct of the study. The data were collected by the first author in her role as a regular volunteer helper at a night-shelter. The covert role can be justified ethically on the grounds that the character of interactions and the social relationships were unaltered from when the researcher was solely in the role of a volunteer. It can be 
justified empirically in that any attempt to adopt a researcher role would have precluded continuing as a helper and would almost certainly have led to uncooperative and/or distorted comments from the homeless. Only questions that would occur naturally were asked, and care was taken not to cause distress. In addition, participants remained anonymous. Hence, there were no 'foreseeable threats to their psychological well-being, health, values or dignity' (British Psychological Society Guidelines, 1997, p. 7).

\section{Participants}

Altogether, 21 people were talked with and observed in a nightshelter for the homeless. Participants were only included in the analysis if the researcher had met them more than once and if sufficient information was gleaned to assess their identity maintenance strategies and their history. All but one were male, and only one was from an ethnic minority. The mean age of the sample was 36.3 years and the mean time spent homeless was 5.9 years.

\section{Procedure}

The researcher had acted as a volunteer at the shelter for two years. This involved a mixture of overnight, evening and morning shifts at the shelter approximately once a fortnight, serving and clearing drinks and meals, preparing beds, giving out clothing and toiletries and chatting with residents. For the fieldwork, a total of 26 hours was spent conversing with homeless individuals over a three-month period, either in the evening or in the morning. Observations and conversations were recorded in a journal at home immediately after each session. Each participant was talked with on at least two occasions during the fieldwork period, but many of them had known the researcher before the study period. Commonly, the researcher greeted new participants with, 'Are you new to (town $\mathrm{x}$ )?' and to previously met participants with a customary, 'How are you?'. If it appeared that the participant wanted to speak with the researcher, as opposed to just wanting access to provisions, then she would sit down with them and allow the participant to direct the conversation; conversation could last from 15 minutes to over an hour. On rarer instances, the researcher would speak with more than one participant at a time, or overhear conversations between the homeless or between the homeless and other volunteers.

\section{TREATMENT OF RESULTS}

At the end of the fieldwork period, the contents of the journal were organized into self-report portraits about each person. Their comments were then analysed individually to ascertain whether they identified with a group label or group members and what their chosen identity maintenance strategy was. The amount of time that each participant had been homeless was based on self-report. Homelessness was not just defined by rooflessness, but by lack of satisfactory accommodation while living a homeless lifestyle. Brief periods when individuals had residences were ignored in calculating longevity of homelessness. 
Table 1. Summary table of participant characteristics

\begin{tabular}{|c|c|c|c|c|}
\hline & $\begin{array}{l}\text { Time } \\
\text { homeless }\end{array}$ & Identity assertions & Strategy used & $\begin{array}{l}\text { Visible } \\
\text { stigmata }\end{array}$ \\
\hline P20 & 2 weeks & $\begin{array}{l}\text { Homeless, area of origin, } \\
\text { skills, likely to escape }\end{array}$ & $\begin{array}{l}\text { Intragroup comparison, } \\
\text { distancing }\end{array}$ & No \\
\hline P19 & 4 months & $\begin{array}{l}\text { Homeless, area of origin, } \\
\text { skills, likely to escape }\end{array}$ & $\begin{array}{l}\text { Intragroup comparison, } \\
\text { distancing }\end{array}$ & No \\
\hline P3 & 1 year & $\begin{array}{l}\text { Homeless, special treatment, } \\
\text { religion }\end{array}$ & $\begin{array}{l}\text { Intragroup comparison, } \\
\text { distancing }\end{array}$ & No \\
\hline P18 & 14 months & $\begin{array}{l}\text { Domiciled, belongings, } \\
\text { achievements, like to escape }\end{array}$ & Denial & No \\
\hline P16 & 18 months & $\begin{array}{l}\text { 'Street evangelist', likely to } \\
\text { escape }\end{array}$ & $\begin{array}{l}\text { Denial, intergroup } \\
\text { comparison }\end{array}$ & Yes \\
\hline P13 & 2 years & Squatter, area of origin & $\begin{array}{l}\text { Creation of comparison } \\
\text { group }\end{array}$ & No \\
\hline $\mathrm{P} 12$ & 2.5 years & $\begin{array}{l}\text { Beggar, personality } \\
\text { characteristics }\end{array}$ & $\begin{array}{l}\text { Creation of comparison } \\
\text { group }\end{array}$ & Yes \\
\hline P14 & 3 years & $\begin{array}{l}\text { Squatter, area of origin, likely } \\
\text { to escape }\end{array}$ & $\begin{array}{l}\text { Creation of comparison } \\
\text { group }\end{array}$ & Yes \\
\hline P6 & 3.5 years & Homeless, drug addict & No comparison & Yes \\
\hline P5 & 4 years & Alcoholic, likely to escape & $\begin{array}{l}\text { Creation of comparison } \\
\text { group }\end{array}$ & No \\
\hline P4 & 5 years & Drinker, carer, area of origin & Intragroup comparison & Yes \\
\hline P9 & 6 years & Drinker & No comparison & Yes \\
\hline P8 & 6 years & Dosser, area of origin, religion & Intragroup comparison & Yes \\
\hline P17 & 7 years & Alcoholic, area of origin & Intragroup comparison & Yes \\
\hline P1 & 8 years & Provider, sharer & Intragroup comparison & Yes \\
\hline P7 & 8 years & Alcoholic, religion & No comparison & Yes \\
\hline P10 & 10 years & Alcoholic, area of origin & No comparison & Yes \\
\hline P11 & 12 years & $\begin{array}{l}\text { Protector, carer, sharer, area } \\
\text { of origin }\end{array}$ & $\begin{array}{l}\text { Intragroup comparison, } \\
\text { identification with } \\
\text { positive group }\end{array}$ & Yes \\
\hline P21 & 12 years & $\begin{array}{l}\text { Special treatment, } \\
\text { disability, drinker }\end{array}$ & $\begin{array}{l}\text { Identification with } \\
\text { positive group }\end{array}$ & Yes \\
\hline P15 & 15 years & Area of origin, drinker, sharer & $\begin{array}{l}\text { Identification with } \\
\text { positive group }\end{array}$ & Yes \\
\hline P2 & 15 years & Dosser, age & No comparison & Yes \\
\hline
\end{tabular}

The identity of participants was determined by their oral report, how they described themselves to the researcher, or how they responded to questions like 'Do you usually stay in the nightshelter?'. The amount of identification with a given group identity was assessed by the manner and rapidity of identity avowal, and identification with group members was assessed by the number of and attachment to homeless friends which were emphasised. For example, an individual was judged to have high identification if they were quick to assert and appeared proud of homeless affiliations, roles and values. Comparisons were again determined by verbal avowal supplemented by researcher questions. Intention to escape homelessness was measured by self-report. The information from each participant was then organised into a summary table in ascending order of time spent homeless (see Table 1). 
Table 2. Summary table of phase characteristics

\begin{tabular}{|c|c|c|c|c|c|c|c|}
\hline Phase & Ps & $n$ & $\begin{array}{l}\text { Time } \\
\text { homeless }\end{array}$ & $\begin{array}{l}\text { Study } \\
\text { identity }\end{array}$ & $\begin{array}{l}\text { Assertions of } \\
\text { individuality }\end{array}$ & $\begin{array}{l}\text { Strategies } \\
\text { used }\end{array}$ & $\begin{array}{l}\text { Visible } \\
\text { stigmata }\end{array}$ \\
\hline 1 & $\begin{array}{l}\text { P3, P19, } \\
\text { P20 }\end{array}$ & 3 & $\begin{array}{l}2 \text { weeks- } \\
1 \text { year }\end{array}$ & Homeless & Yes & $\begin{array}{l}\text { Distancing, } \\
\text { intragroup } \\
\text { comparison, } \\
\text { escape }\end{array}$ & No \\
\hline 2 & P16, P18 & 2 & $\begin{array}{l}\text { 14-18 } \\
\text { months }\end{array}$ & $\begin{array}{l}\text { Non- } \\
\text { homeless }\end{array}$ & Yes & Denial & Mixed \\
\hline 3 & $\begin{array}{l}\text { P5, P12, } \\
\text { P13, P14 }\end{array}$ & 4 & $2-4$ years & $\begin{array}{l}\text { Homeless } \\
\text { type }\end{array}$ & No & $\begin{array}{l}\text { Creation of } \\
\text { comparison } \\
\text { groups }\end{array}$ & Mixed \\
\hline $4 a$ & $\begin{array}{l}\text { P1, P4, P8, } \\
\text { P11, P17 }\end{array}$ & 5 & $5-12$ years & $\begin{array}{l}\text { Dossers/ } \\
\text { drinkers }\end{array}$ & Yes & $\begin{array}{l}\text { Intragroup } \\
\text { comparison }\end{array}$ & Yes \\
\hline $4 b$ & $\mathrm{P} 15, \mathrm{P} 21$ & 2 & $\begin{array}{l}12-15 \\
\text { years }\end{array}$ & Family & No & $\begin{array}{l}\text { Identification } \\
\text { with positive } \\
\text { group }\end{array}$ & Yes \\
\hline $4 c$ & $\begin{array}{l}\text { P2, P6, P7, } \\
\text { P9, P10 }\end{array}$ & 5 & $\begin{array}{l}3.5-15 \\
\text { years }\end{array}$ & $\begin{array}{l}\text { Dossers/ } \\
\text { drinkers }\end{array}$ & No & $\begin{array}{l}\text { No } \\
\text { comparison }\end{array}$ & Yes \\
\hline
\end{tabular}

\section{RESULTS}

The initial problem was to allocate individuals to categories on the basis of the similarities and differences of their identity maintenance strategies. At this stage the longevity of their homelessness was not a criterion. However, initial results were consistent with the idea that the strategies did, however, fall into four main phases. For ease of presentation and subsequent discussion of the validity of the provisional generalizations, the analysis is presented using the temporal framework.

Inspection of Table 1 and of the identity maintenance strategies identified indicate the potential utility of a four-phase separation: homeless for less than a year, 14-18 months, two to four years and over five years. The last phase was further subdivided. The main characteristics of each phase are summarized in Table 2 and are described in more detail below.

Phase 1 ( < 1 year): Aspirant exiters ${ }^{1}(n=3)$ (P3, P19, P20)

Although each of the Phase 1 men identified themselves as homeless, P19 and P3 were more reluctant to do so than P20. None of these identified with other homeless people, but distanced themselves both behaviourally and cognitively. P19 and P20 associated only with each other, whilst P3 acted like and associated with the volunteers. All three talked extensively about ceasing to be homeless, making favourable intragroup comparisons by stressing their skills, travel experience and coping abilities. For example, P20 said that he was amazed at the number of beggars nowadays and contrasted himself and P19 with them: 'Me and (P19) are classified as homeless but we're doing all right'. P3 also made favourable intragroup comparisons

\footnotetext{
${ }^{1}$ With thanks to reviewer $\mathrm{C}$ for suggesting this label. 
by stressing that he was one of the select few homeless people allowed to have his post sent to the shelter. No intergroup comparisons were observed. These comments are consistent with P3, P19 and P20 being aspirant exiters.

\section{Phase 2 (14-18 months): Deniers $(n=2)$ (P16, P18)}

The main strategy of Phase 2 was denial of group membership: denying homeless identity and asserting a new one. P18 stressed that he was a typical domiciled person and saw himself as successful: 'got my own flat, my own clothes, my own business'. However, in fact his flat had no kitchen, and his business consisted of his offering to be a DJ, but he had not worked for at least six months. He explained his unkempt appearance by stating that he preferred to look less 'sharp' to avoid negative police attention. P18 made no comparisons. Likewise, P16 did not identify himself as homeless, but did make downward comparisons with the homeless: 'You think I'm like these other old dossers don't you? I'm not, I'm the street evangelist and I've got a degree and everything'. Although the Phase 2 people denied that they were homeless, they talked about leaving their situation, P18 was making plans to choose an accepting place to live, and P16 talked about going back to university. Like P3, P19 and P20, P16 and P18 were attempting social mobility.

Phase 3 (2-4 years): Subgroupers $(n=4)$ ( P5, P12, P13, P14)

Persons in Phase 3 appeared to be utilizing social creativity, where both the dimensions and the group for comparisons were chosen for self-enhancement. They identified themselves with a subgroup of homeless people and used this identity for favourable intergroup comparisons with the homeless. P12 identified himself as a beggar and compared his ingroup favourably with New Age Travellers. P13 and P14 achieved a positive identity by remarking that they had a squat, thereby distancing themselves from the homeless who stayed in the night-shelter. On the suggestion that they might stay in the night-shelter, P13 and P14 looked affronted and P13 said 'We don't stay. We never stay'. P5 said that he did not want to have to come to the shelter any more and talked about the homeless who had been coming to the shelter for five to six years and how he was different from them. He spoke more to the volunteers and appeared to have only limited contact with other homeless people. P5 identified himself as someone who would escape homelessness and described his plans to go to a hostel.

\section{Phase 4 ( $>3.5$ years)}

Within the longer-term homeless, of whom there were 12, there was a subgroup of people who P11 and P15 referred to as 'one big family'. They shared resources, supported each other and frequently associated together. All members, except P1, had street names portraying their area of origin $(\mathrm{P} 10, \mathrm{P} 11, \mathrm{P} 15)$ or physical characteristics (P21). Although this is a natural group of the homeless, they can be classified into subcategories based on their use of different identity maintenance strategies. Only P11, P15 and P21 identified themselves with the family to the extent that they talked about it much of the time and derived comfort and importance from their membership. Of these three people, P11 made intragroup comparisons and is therefore placed in Phase 4a, while P15 and P21 are in Phase 4b. 
Phase $4 a$ ( $>5$ years): Carers and sharers $(n=5)(P 1, P 4, P 8, P 11, P 17)$

Phase 4a homeless identified themselves with homeless people yet made no intergroup comparisons. Instead, they made intragroup comparisons, most noticeably on dimensions of helping behaviour. Except for P8, Phase 4a persons stressed that they had a caring, protecting role in the homeless community and drew attention to their helping behaviour. For example, P1 shared his food, clothing, cigarettes and knowledge with other homeless people, pointing out that: 'I know not everybody would, but if I've got something and if someone else wants it then I'll give them half'. P17 looked after one of his friends who had collapsed, continually emphasizing that he was helping. On other occasions, P17 made an effort to cheer up other homeless people. Further, when P11 was annoyed after a homeless person did not want his help after an injury he stated: 'I don't know why I bother sometimes. I spend most of every day seeing to people. I could just sit about like the others'. People in this sub-category perceived themselves as different from other homeless people. For example, after a volunteer had refused her request to look for clothing in the volunteers' area, P4 shouted: 'You can't treat me like this, I'm not like the rest of them, I won't be treated like this. I'm different'.

P8 is a difficult participant to categorize. There are at least two possible explanations for the strategies that he was using. For example, P8 asked the researcher on two occasions, 'Why do you come and be with dossers like us?' and asserted that his ingroup members were rude to the volunteers. The ambiguity here is whether this served positively to discriminate himself from ingroup members on dimensions of rudeness (favourable intragroup comparison) or if it accentuated the lowstatus position of the ingroup in addition to identifying with the low-status group (unfavourable intergroup comparison). Alternatively, both functions may be served simultaneously.

\section{Phase $4 b$ ( $>5$ years): Family $(n=2)(P 15, P 21)$}

The two people in this subcategory saw themselves as part of a subgroup of homeless people and appeared to gain positive affect from this identity. There was little attempt to assert individual identities and neither of them made any explicit comparative statements. They categorized themselves as 'drinkers', and talked fondly about their group and of the advantages that having such friends made to their lives. For example, P21 talked at length about his friendship and past exploits, particularly with P11, and P15 stated that no-one would be able to hurt him in the night-shelter because he was among his friends.

Phase $4 c$ ( $>3.5$ years): Typicals $(n=5)(P 2, P 6, P 7, P 9, P 10)$

No intragroup or intergroup comparisons were noted during conversations with those in Phase 4c. In fact, P9 accentuated ingroup similarity in stating: 'We're all in exactly the same situation' and P2 categorized himself as a 'typical dosser'. Although P10 was identified by others as a member of the family, he did not identify himself as such; instead P10 lamented that he was a prototypical 'old alcoholic'. The people in this phase were acutely aware of their stigmatized position. For example, P10 did not want his family to see him, saying 'What must they think when they see me on the 
other side of the road?'. P7 said he did not like public places because of the way people looked at him. P6 exclaimed: 'I'm a person too, I hate the way people look at me'.

\section{DISCUSSION}

Although it is conventional to examine the methodology and hypotheses at the beginning of the discussion, a tentative model of the progressive development of strategies of identity maintenance over time will be offered first to provide a framework for subsequent critical evaluation.

\section{Provisional model}

Although this study provides a snapshot account only, because the longevity of homelessness seemed to be a significant factor affecting a differential use of identity maintenance strategies, a career of homelessness can be tentatively proposed where individuals progress with time through the identified typologies. The model suggested has been amended in accordance with estimations of the order of the biographies of the participants and with previous research (see Figure 1).

Phase 1: Aspirant Exiters. Initially individuals appear to identify themselves as homeless but make personally favourable intragroup comparisons with other homeless people on the basis of their past accomplishments and the perceived likelihood of escaping from homelessness. At this point, escape from homelessness, given available and appropriate opportunities, is quite likely. However, as time progresses, escape may begin to be seen as increasingly unlikely and hence lose its utility as a basis for favourable intragroup comparisons. At the same time, the use of past accomplishments as a comparison dimension may be getting 'worn out'. Values are likely to become more analogous to those of the ingroup; alternatively, the temporal focus of the individual may be changed to avoid thinking about negative past events. These changes, appearing to occur after a year or so of homelessness, necessitate a search for a new identity maintenance strategy.

Phase 2: Deniers. At this point the individual, bereft of coping strategies, may deny his/her reality. If a homeless identity is repeatedly denied, then the individual may eventually come to internalize the alternative identity asserted, facilitating escape. Although minor self-deception is normal (Taylor, 1989), such extreme selfdeception is not understood. It may exacerbate to such an extent that the individual engages in the kinds of bizarre behaviour that Snow and Anderson (1993) noted is often labelled as mental illness.

Phase 3: Subgroupers. While an individual can selectively associate with other homeless people and retain an ability to control his/her lifestyle, for example by remaining independent of night-shelters, such differences can be utilized to locate a group within the homeless against which to make favourable intergroup comparisons. However, as time progresses, homeless people may increasingly lose control over their associations and lifestyle, and hence this strategy becomes impractical. Again, the search for a new strategy may commence. 


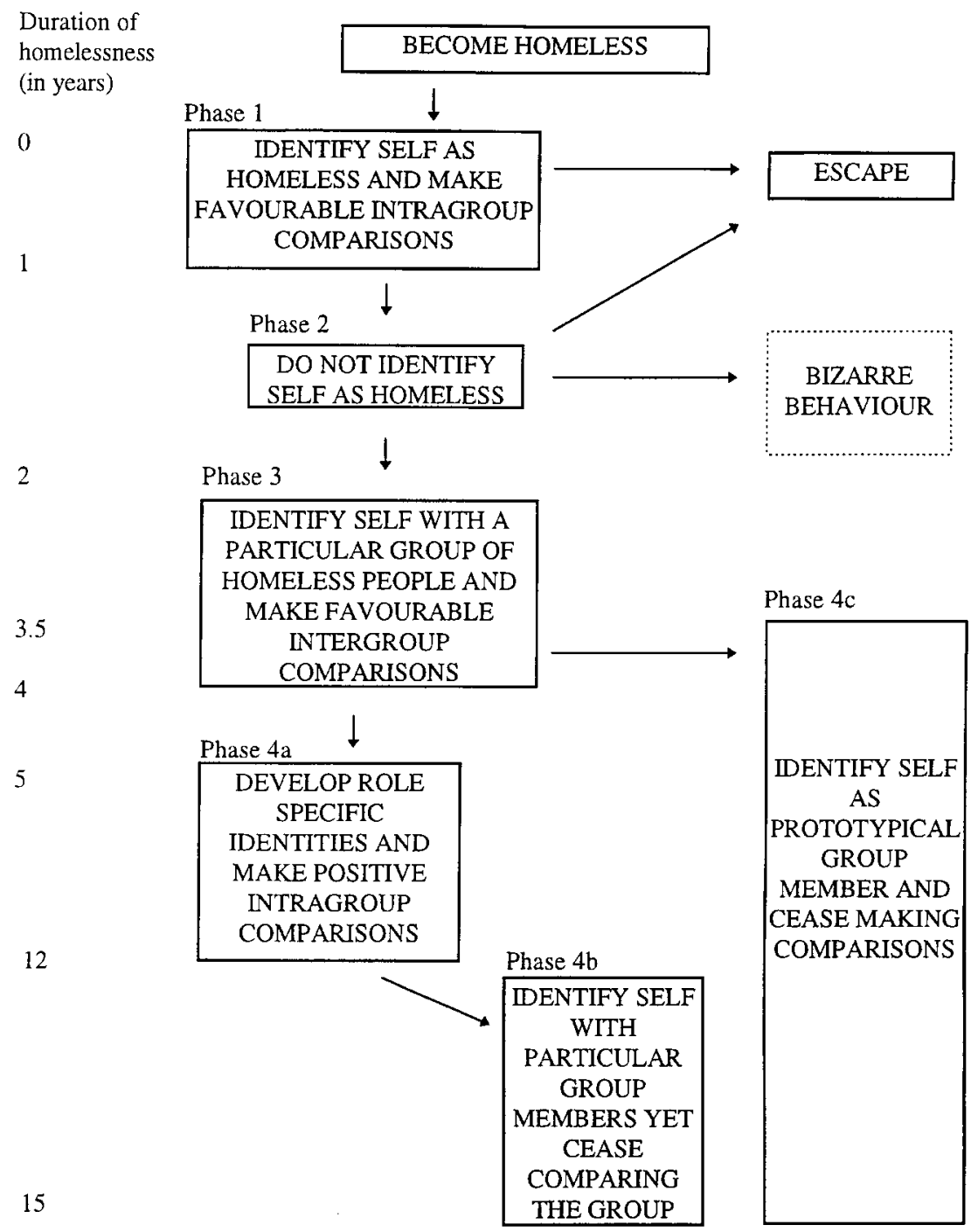

Figure 1. Provisional model

Phase 4. The type of identity maintenance strategy that an individual uses after several years of homelessness is dependent on many factors. Once a member of Phase 4, it will be difficult to escape because self-esteem becomes dependent on identifications integral with homelessness:

- Phase 4a: Carers and Sharers. If positive role-specific identities can be created, then the individual can use these for favourable intragroup comparisons. This may depend on personality factors, for example, being sociable. Past personal experience can be used: P11 may have easily created a role-specific identity because of his previous job in health care and $\mathrm{P} 4$, being female, may have found it easier to adopt a caring role. 
- Phase 4b: Family. Characteristics such as a disability, as in the case of P21, may preclude membership of Phase $4 \mathrm{a}$, and therefore lead to the adoption of Phase $4 \mathrm{~b}$ strategies. However, the route to Phase $4 \mathrm{~b}$ may also be via Phase $4 \mathrm{a}$. For example, P15 had contributed many resources to 'the family' in the past, and hence had a role-specific identity as a provider. As he grew older and weaker, his own survival and consequently his identity increasingly depended on other group members and he ceased making intragroup comparisons.

- Phase 4c: Typicals. It is possible that a failure to develop a role-specific identity or close ingroup affiliations may lead eventually to self-categorization as a prototypical homeless person. This seemed to be the case for P2, P6 and P9, each of whom was treated badly by the other homeless. For example, they were teased, had their belongings stolen and were not included in the sharing of resources. However, why P10 did not use the strategies of $4 \mathrm{a}$ or $4 \mathrm{~b}$ remains unclear, as he was an accepted family member and he shared resources. It is possible that the strategy used in Phase 1 of favourable intragroup comparisons on the basis of previous accomplishments was so successful for P10, due to his previous high status, that it did not 'wear out' as quickly as for the other homeless. This may have inhibited the development of other strategies and led to P10 progressing from Phase 1 directly into Phase 4c.

\section{Progression}

The exact nature of progression and its possible alternatives remains unclear, although sudden switches between strategies seem unlikely. It is possible that changes result from resolutions of individual identity crises, and likely that progression is affected by other factors, such as increasing dependence on alcohol.

The current provisional model shows some pathways as bi-directional. For example, P5 may have been returning to Phase 1 (aspirant exiters) from Phase 4c (typicals). Although he made intergroup comparisons, as he increasingly dissociated himself from other homeless people, he may also have used intragroup comparisons like Phase 1. The uni-directional arrows are not intended to be wholly determinist; they are intended to indicate the most likely direction of change. The timetable must also vary from individual to individual as a function of variability in circumstances and personality.

\section{Evaluation of generalizations and provisional model}

(1) As expected, attempts at social change were not observed as an identity maintenance strategy. The only possible exception was P12. He did aim to maintain a positive social representation of his ingroup, but this did not seem to be motivated by a desire for future favourable comparisons. He identified himself as a beggar and said that he hated New Age Travellers for giving the public the impression that beggars were rude. However, the reason for this seemed to be that he stood to lose money rather than self-esteem if the social representation of his ingroup was negative in the eyes of the public.

(2) That the longer-term homeless will have a stronger homeless identification is broadly supported in the data. Although Phase 1 (aspirant exiters) did identify themselves as homeless, it was not a strongly avowed identity, and they did not identify with ingroup members. Phase 2 (deniers) did not identify themselves as 
homeless. Phases 3 (the subgroupers), 4a (carers and sharers) and 4b (family) clearly identified themselves with ingroup members rather than with the label, and Phase 4c (typicals) clearly identified themselves with the label and with ingroup members.

(3) That the shorter-term homeless will be more likely to use strategies related to social mobility to maintain identity was supported: Phase 1 distanced themselves from group members and emphasized attempts to leave the group; and Phase 2 denied the group categorization. However, there was only partial support for the premise that these strategies would be followed by comparison, because, for example, P18 (of Phase 2: deniers) asserted his domiciled identity without comparison.

(4) The strategy of creating a comparison group from within the ingroup was found in the four people who had been homeless for between two and four years. Interestingly, this strategy was not used by P7 and P9, who had been homeless longer, even though they did not stay at the night-shelter. It is possible that this was because after four years an individual becomes too enmeshed in homelessness to distinguish a subgroup for comparisons.

(5) Since none of the participants made intergroup comparisons using the general group of homeless people as their ingroup, none saw the homeless as being high on trustworthiness and altruism. In fact, most of the homeless saw each other as untrustworthy. They handed in their valuables to the volunteers (P7, P11, P18) and were wary of each other (P5, P8). For example, P11 said that anyone could have been responsible for P21's death (he died during the fieldwork period), and P4 accused everyone when her cider went missing. Nevertheless, participants trusted their close ingroup members and perceived them as altruistic and sharing. Indeed, these two dimensions were particularly highly valued, presumably because they served to enhance distinctiveness and positive identity.

(6) Although five of the 11 who had been homeless for over five years made intragroup comparisons and avoided intergroup comparisons, Phase 1 (aspirant exiters) also used this strategy.

(7) Three of the five long-term homeless who made favourable intragroup comparisons (Phase 4b) did assert role-specific identities of carer, sharer and protector. In contrast, the intragroup comparisons of Phase 1 (aspirant exiters) were based on dimensions largely independent of homelessness.

(8) The suggestion that some of the long-term homeless may not make intergroup or intragroup comparisons was also supported. In total, of the 21 homeless, eight did not make comparisons, of whom six were long-term.

\section{Critical evaluation}

The co-variation of identity maintenance strategies with longevity of homelessness can only be hypothesized from this study, because of both the small numbers involved and the cross-sectional nature of the design. A longitudinal study based on a larger sample would be required to evaluate whether the biographical reports supplied in the study were valid and representative.

The interpretations offered are based on less evidence than is desirable, and the researcher had less time with several participants than she would have preferred. The range of identity maintenance strategies being used may also have been under- 
estimated. In part, this was because participants attended the night-shelter less frequently than expected. Furthermore, the attentional demands of participants P1 and P11 reduced time available for others. The main hazard was the unavoidable attrition which reflects some of the difficulties of the homeless: in the second week of study P22 died; half-way through the study P13 and P14 were banned from the nightshelter; P3 left town; and two months into the study P1 was imprisoned. Such complications would be likely to affect any longitudinal study of the homeless to a similar extent.

The sampling was opportunist, being confined to those attending the particular shelter and with whom adequate conversational relationships could be formed. Noone approached was subsequently dropped. A decision was taken not to approach young people dependent on illegal substances. Empirically, however, the findings are comparable with those of Snow and Anderson (1987, 1993), who spent 405 hours with a seemingly representative sample of 168 homeless people. This implies that the methodological weaknesses did not give rise to misleading results.

If findings reported are valid and if the classifications and their interpretations are sound, there are important implications for SIT. First, this study has shown a range of ingenious strategies devised to maintain a favourable identity in a low-status group. Some of these have not been reported previously: the invention of a comparison group, the avoidance of intergroup comparisons, a viable identity based simply on categorization, and not making any social comparisons.

The reasons suggested by Tajfel and Turner (1979) for people using different strategies appear to have been both supported and extended. Since Phase 1 (aspirant exiters) made intragroup comparisons, it implies that it is not, as Crocker and Major (1989) proposed, that the different strategies take time to be developed; but that the suitability of different strategies changes with the longevity of homelessness, mediated by combinations of the perceived immutability of social relations, identification with the social group and other group members, individual experiences and personality variables. It is likely that any or all of these factors influence the self-enhancement opportunities of each strategy.

It is likely that the issue of the relative salience of PI or SI is more complex than is implied by the idea of the 'appropriateness' of the identity in the situation (Oakes, 1987). Salience may also be determined by an interaction between situation, individual and group characteristics, with the aim of an outcome intended to minimize negative self-esteem. For example, those in Phase 4a (the carers and sharers), were aware of the low-status position of their ingroup but were still able to make favourable intragroup comparisons, preferring PI to be salient and thereby avoiding the salience of their homeless SI. Not all components of SIs were avoided in this phase; identification with their area of origin was asserted by the majority of participants.

The results support Turner's (1982) proposal for differentiating between identifications with ingroup members and with the group label. If fact, in this study these two possibilities seemed to have distinguishable developmental paths with increased longevity of homelessness. In addition, the degree of identification with the group and group members appeared to interact with self-enhancement and survival needs. Those in Phase $4 \mathrm{a}$ (carers and sharers) and $4 \mathrm{~b}$ (family) could avoid identification with ingroup members because they were relying on them for survival and self-enhancement. In contrast, those in Phase 4c (typicals) were not reliant on other people and did not identify with the other homeless. 
Although the nature of this research was preliminary, it appears then that some of the proposals of SIT may be misleading. Tajfel (1981) stated that meaning and positive affect from identity cannot be gained without comparison. Turner et al. (1987) also claimed that comparison is necessary for both SI salience and categorization. However, in this study, eight of the 21 participants made no comparative statements, and yet these participants appeared to categorize themselves and have a salient SI. In addition, for P18 and the members of Phase $4 \mathrm{~b}$ their chosen identity maintenance strategy appeared to be successful. This leaves a minority of 10 out of 21 actually offering explicit comparisons.

Further, the identities of Phase $4 \mathrm{c}$ (typicals) do not seem to be favourable. It is feasible that an inability to make comparisons led to low self-esteem in this phase. Alternatively, it is possible that making comparisons is a learned behaviour stimulated by a threatened identity, which is more likely to recur if previous comparisons have yielded positive outcomes, but less likely if they have resulted in negative outcomes; they will be conditioned away if there is no positive reinforcement.

\section{Helping the homeless}

Despite the fact that the participants in this study were a small unrepresentative group and the model proposed remains unevaluated except against the current results and extant literature, preliminary recommendations can be made for addressing the difficulties and dilemmas of the homeless. The model implies that the probability of escaping from the full trajectory diminishes the longer someone remains homeless, and that any intervention should take into account as its point of departure just which identity maintenance strategies are currently being deployed by a homeless person.

It is hypothesized that escape is more likely if an individual does not come to identify with other homeless people, as in Phases 1 (aspirant exiters) and 2 (deniers). In order for individuals to remain in Phase 1 they must continue to believe that escape from homelessness is feasible and probable. The provision of access to adequate housing, employment and support at this stage could halt the progression and facilitate re-integration into the wider community. The non-homeless identities of Phase 2 could also be cultivated by provision of housing and employment, and halt their retreat into alternative realities or bizarre behaviour.

However, for those homeless whose positive identities have become more entrenched in homelessness, merely providing housing and employment is unlikely to facilitate escape. For these individuals, opportunities would need to be created which promoted the development of a positive personal and social identity which was independent of homelessness; for example, constructive personal and occupational therapy might be used to cultivate a sense of self-efficacy. Employment would help the homeless have a positive non-homeless identity and simultaneously be incompatible with a homeless lifestyle (Hagan and McCarthy, 1997).

In the meantime, any housing which is provided for the longer-term homeless needs to be geographically close to other ingroup members with whom bonds have been established. This was highlighted by the plight of P17 and P22. P17 was allocated housing six miles from his street community, felt isolated and suicidal, and had vowed not to use the flat. P22 had a similar experience, did not use his flat, and died, in part from pneumonia developed on the streets. After the survival and identity of individuals has become dependent on their homeless affiliations, providing 
accommodation far from their social support networks is tantamount to a sentence of solitary confinement. The benefits of a home fail to overcome the costs of losing the basis of a tolerable identity.

Some of the people in this study were aware of these issues. For example, P5 said he realized that he would have to distance himself from other homeless people in order to escape his situation. P5 was aware and prepared to do this; he was not a member of a particular homeless subgroup and was ridiculed by the other homeless. In contrast, the homeless whose identity was firmly situated within relationships with other homeless would have their sense of self-worth threatened by leaving their situation.

Hence, there is a cruel paradox: people who maintain the most positive identities while homeless do so by identifying more strongly with the homeless role and within a supportive group of friends. However, these same strategies inhibit escape.

One solution to this dilemma was provided by P11, who said that he was going to give up alcohol in order to look after his street friends. This would not only allow P11 a way out of his negative position, but would allow him to continue the previous basis for his positive identity whilst separate from homelessness.

While these proposals assume that an individual's quality of life will be ameliorated by escaping from homelessness, it may be that the positive characteristics of Phases $4 \mathrm{a}$ (carers and sharers) and $4 \mathrm{~b}$ (family) can be maintained without the physical hardships of homelessness by the creation of communities with interdependent roles for each individual to fulfil.

It is vital that identity maintenance processes are taken on board by policy makers and practitioners dealing with the homeless. As argued above, it is when a tolerable identity depends on the individual being homeless that the likelihood of the individual leaving the subculture becomes minimal.

\section{REFERENCES}

Anderson, L., Snow, D. A. and Cress, D. (1994) 'Negotiating the public realm: stigma management and collective action among the homeless', Research in Community Sociology, 1, 121-143.

Barnett, A. (1997) 'Poor kept on the outside looking in', The Observer (Business Section), 29 September, p. 6.

Baumann, D. and Grigsby, C. (1988) Understanding the Homeless: From Research to Action, Hogg Foundation for Mental Health, Austin, TX.

Breakwell, G. M. (1986a) Coping with Threatened Identities, Methuen, London.

Breakwell, G. A. (1986b) 'Identities at work', in H. Beloff (ed.), Getting into Life, pp. 43-66, Methuen, London.

Breakwell, G. M. (1992) 'Processes of self-evaluation: efficacy and estrangements', in G. M. Breakwell (ed.), Social Psychology of Identity and the Self Concept, pp. 35-55, Surrey University Press, London.

British Psychological Society (1997) Code of Conduct, Ethical Principles and Guidelines, Chartwell Press, Leicestershire.

Cohen, C. I., Teresi, J., Holmes, D. and Roth, E. (1988a) 'Survival strategies of older homeless men', The Gerontologist, 28, 58-65.

Crane, M. (1990) Elderly Homeless People in Central London, Age Concern England and Age Concern Greater London, London.

Crocker, J. and Major, B. (1989) 'Social stigma and self-esteem: the self-protective properties of stigma', Psychological Review, 96, 608-630. 
Deaux, K., Dane, F. C., Wrightsman, L. S. and Sigelman, C. K. (1993) Social Psychology in the '90s, Brooks/Cole, Pacific Grove, CA.

Festinger, L. (1954) 'A theory of social comparison processes', Human Relations, 7, 117-140.

Fischer, P. J. and Breakey, W. R. (1991) 'The epidemiology of alcohol, drug and mental disorders among homeless persons', American Psychologist, 46, 1115-1128.

Fisher, K. and Collins, J. (1993) 'Introduction', in K. Fisher and J. Collins (eds), Homelessness, Health Care and Welfare Provision, Routledge, London.

Foddy, M. and Crundall, I. (1993) 'A field study of social comparison processes in ability evaluation', British Journal of Social Psychology, 32, 287-305.

Grigsby, C., Baumann, D., Gregorich, S. E. and Roberts-Gray, C. (1990) 'Disaffiliation to entrenchment: a model for understanding homelessness', Journal of Social Issues, 4, 141-156.

Hagan, J. and McCarthy, B. (1997) On the Street: Street Youth and Crime, Cambridge University Press, Cambridge.

Hombs, M. E. (1992) 'Reversals of fortune: America's homeless poor and their advocates in the 1990s', New Formations, 17 (Summer), 109-125.

Karasawa, M. (1988) 'Effects of cohesiveness and inferiority upon ingroup favouritism', Japanese Psychological Research, 30, 49-59.

Kelling, K. (1991) Older Homeless People in London, Age Concern, London.

Larkin, M-J. (1995) 'What's the story?', Bacas (U.W.E. Magazine), Spring Term edn., pp. 18-19.

Oakes, P. (1987) 'The salience of social categories', in J. C. Turner, M. A. Hogg, P. J. Oakes, S. D. Reicher and M. S. Wetherell (eds), Rediscovering the Social Group: A Self Categorization Theory, pp. 117-141, Blackwell, Oxford.

Phillimore, P. (1979) 'Dossers and jake drinkers: the view from one end of skid row', in T. Cook (ed.), Vagrancy: Some New Perspectives, pp. 29-48, Academic Press, London.

Pollio, D. E. (1994) 'Wintering at the Earle: group structures in the street community', Social Work with Groups, 17, 47-70.

Pollio, D. E. (1995) 'Group membership as a predictor of service use related behaviors for persons "on the streets", Paper presented at The National Symposium for Empirical Groupwork, May.

Pollio, D. E. and Kasden, A. (in press) "WWalking around with a question mark on your head": social and personal constructs among persons "on the streets", Journal of Applied Social Services.

Rossi, P. H., Wright, J. D., Fisher, G. A. and Willis, G. (1987) 'The urban homeless: estimating composition and size', Science, 235, 1336-1341.

Russell, B. G. (1991) Silent Sisters: A Study of Homeless Women, Hemisphere, London.

Sandford, J. (1971) Down and Out in Britain, Peter Owen, London.

Snow, D. A. and Anderson, L. (1987) 'Identity work among the homeless: the verbal construction and avowal of personal identities', American Journal of Sociology, 92, 1336-1371.

Snow, D. A. and Anderson, L. (1993) Down on Their Luck: A Study of Homeless Street People, University of California Press, Berkeley, CA.

Snow, D. A., Anderson, L. and Koegel, P. (1994) 'Distorting tendencies in research on the homeless', American Behavioral Scientist, 37, 461-475.

Tajfel, H. (1978) Diffentiation Between Social Groups: Studies in the Social Psychology of Intergroup Relations, Academic Press, London.

Tajfel, H. (1981) Human Groups and Social Categories, Cambridge University Press, Cambridge.

Tajfel, H. (1982) Social Identity and Intergroup Relations, Cambridge University Press, Cambridge.

Tajfel, H. and Turner, J. C. (1979) 'An integrative theory of intergroup conflict', in W. G. Austin and S. Worchel (eds), The Social Psychology of Intergroup Relations, Brooks/Cole, Monterey, CA.

Taylor, S. E. (1989) Positive Illusions: Creative Self-Deception and the Healthy Mind, Basic Books, New York.

Turner, J. C. (1981) 'The experimental social psychology of intergroup behaviour', in J. C. Turner and H. Giles (eds), Intergroup Behaviour, Ch. 3, Blackwell, Oxford. 
Turner, J. C. (1982) 'Towards a cognitive redefinition of the social group', in Tajfel, H. (ed.), Social Identity and Intergroup Relations, pp. 15-40, Cambridge University Press, Cambridge.

Turner, J. C., Hogg, M. A., Oakes, P. J., Reicher, S. D. and Wetherell, M. S. (1987) Rediscovering the Social Group: A Self Categorization Theory, Blackwell, Oxford.

Wills, T. A. (1981) 'Downward comparison principles in social psychology', Psychological Bulletin, 90, 245-271. 